\title{
INNOVACIÓN ADMINISTRATIVA Y VENTAJA COMPETITIVA EN ÉPOCAS DE TURBULENCIA
}

Julio López Mas (*)

E-mail: johans_jlopez@yahoo.com

\section{RESUMEN}

Para enfrentar las condiciones cambiantes y de alta incertidumbre de los mercados internacionales, las empresas tienen que orientar sus capacidades y recursos a construir ventajas competitivas durables. La innovación administrativa desarrollada en forma sistémica es única en cuanto a su capacidad para crear ventajas sostenibles difíciles de copiar por la competencia. Para este propósito, es necesaria una renovación de los principios, teorías y prácticas de la administración moderna.

Palabras clave: Turbulencia Económica, Ventaja Competitiva, Innovación Administrativa, Renovación del Pensamiento Administrativo.

\section{ABSTRACT}

To meet changing conditions and high uncertainty of international markets, companies must focus their capabilities and resources to build durable competitive advantages. Management innovation systemically developed is unique in its ability to create sustainable advantages difficult to copy by competitors. For this purpose, we need a renewal of the principles, theories and practices of modern management.

Key words: Economic turbulence, Competitive Advantage, Innovation Management, Administrative Thought Renewal.

(*) Doctor en Historia de las Economías y Sociedades, EHESS, París. Profesor Principal y Director del Instituto de Investigaciones de la Facultad de Ciencias Administrativas de la UNMSM. 


\section{INTRODUCCIÓN}

Con la crisis financiera internacional desatada en el 2008, cuyos orígenes se remontan a años anteriores, tomamos conciencia que el mundo está cada vez más interconectado y más interdependiente, y también que el panorama económico presenta importantes niveles de fragilidad entrelazada. Pareciera que la turbulencia, el caos, el riesgo y la incertidumbre son la nueva condición normal de industrias, mercados y empresas.

El panorama internacional es inestable: la turbulencia genera vulnerabilidad contra la cual las empresas necesitan defenderse y protegerse pero, al mismo tiempo, se abren oportunidades para el desarrollo y el éxito empresarial. Las empresas deben adoptar nuevas visiones, principios y prácticas administrativas para reducir su vulnerabilidad y aumentar su viabilidad a largo plazo.

Dos importantes obras recientemente publicadas nos proporcionan interpretaciones sugerentes y propuestas novedosas para entender y orientar la realidad empresarial actual, las cuales son el motivo del presente artículo.

Gary Hamel y Bill Breen son los autores de "El futuro de la Administración". En esta obra sostienen que las empresas, en la actual era de cambios vertiginosos, necesitan de una gestión audaz e innovadora en un mundo donde la adaptabilidad y la creatividad son el motor del éxito empresarial.

Philip Kotler y John A. Caslioni son los autores de "La Ciencia del Caos. El Management y el Marketing en la era de las turbulencias" ${ }^{2}$. Plantean que la turbulencia es la nueva normalidad, con rachas periódicas e intermitentes de prosperidad y declives económicos, y por esto las empresas necesitan renovar el sistema de gestión para épocas de caos integrando, entre otros elementos, un sistema de alerta temprana, la construcción de escenarios clave y la selección de estrategias en función de la priorización del escenario y de la actitud ante el riesgo.

Al igual que la eficiencia, la escala y el control representaron desafíos para las empresas del siglo XX, Hamel y Breen afirman que son tres los retos más importantes que deben afrontar las empresas en el siglo XXI:
- Acelerar drásticamente el ritmo de la renovación estratégica tanto en las organizaciones grandes como en las pequeñas.

- Convertir la innovación en el trabajo de todo el mundo.

- Crear un entorno laboral muy atractivo, que inspire a los empleados a dar lo mejor de sí mismos.

La idea fuerza es que la innovación de la administración y gestión permite a las empresas crear ventajas de largo plazo.

\section{NUEVA ESCENA ECONÓMICA MUNDIAL}

La mayor interconectividad e interdependencia del mundo actual supone un mayor riesgo para las empresas y hacen necesario un nuevo marco estratégico para operar frente a turbulencias intermitentes e impredecibles. La turbulencia en los negocios se refiere a aquellos cambios rápidos e impredecibles que se producen en el entorno externo o interno de las empresas y que afectan su rendimiento.

Kotler y Caslione plantean que la turbulencia económica asume características especiales en un mundo cada vez más globalizado. Se identifica un contraste entre tiempos de ciclo económico normal y economías turbulentas. A lo largo de la historia de los negocios siempre han existido niveles de turbulencia (a niveles macro: local, regional o global, y nivel micro: empresas particulares). En el pasado las amplias oscilaciones han durado varios años, y eran de alguna manera movimientos predecibles, pero en la economía de la nueva normalidad la turbulencia de alta intensidad es profundamente distinta.

"Hoy en día, y en un futuro previsible, la economía de la nueva normalidad es más que una sucesión de ciclos alcistas y bajistas de tiempos normales que, al fin y al cabo, aportaban cierta predictibidad a las negocios a nivel macro. Actualmente podemos esperar mayores sacudidas y más dolorosas disrupciones que causarán un elevado y generalizado riesgo y gran incertidumbre en los negocios, tanto a escala micro como macroeconómica"3.

Los principales factores que provocan cambio y turbulencia incluyen: avances tecnológicos y la

1 Hamel, Gary y Breen, Bill. (2008).

2 Kotler, Philip y Caslioni, John A. (2009).

3 Kotler. (2009). Pág. 32. 
revolución de la información, tecnologías disruptivas e innovaciones, la hipercompetitividad, y el poder del consumidor.

Se ha pasado de la era industrial a la postindustrial, del sistema de producción estandarizado en masa a los sistemas flexibles de producción que han favorecido la globalización del comercio en las últimas décadas.

Al final de los años 70 se desarrollaron los sistemas flexibles de producción que suponen cambios radicales en la manera de gerenciar respecto de la teoría administrativa clásica. El énfasis ya no está en la producción (producir de manera masiva con bajos costos unitarios y luego lograr la venta de lo producido mediante un buen mercadeo), sino en el mercado: producir lo que el comprador desea comprar.

El sistema flexible permite series más pequeñas y adaptadas a los requisitos de la demanda, así como rápidos cambios en las series de producción. Los sistemas de información avanzados permiten el contacto directo con los proveedores y con los distribuidores, de tal manera que hacen innecesaria la permanencia larga de materias primas y productos terminados en los almacenes. Se produce lo que el mercado demanda y se satisface al cliente inmediatamente.

Kenichi Ohmae, uno de los estrategas de negocios y corporativo más destacado nos habla del futuro corporativo en la economía global en su libro "El próximo escenario Global":

"La compañía exitosa (...) debe ser un nuevo fenómeno, que tendrá muy poco que ver con sus antecesores. Si la comparamos con un ser humano, esa compañía tiene que volverles la espalda de manera definitiva a sus parientes y antepasados: debe ser genéticamente diferentes de ellos. (...).Las compañías deben comprometerse con la innovación como nunca antes (...) necesitan heterogeneidad en su plataforma corporativa (...) puesto que no existe jerarquía alguna en el proceso de concebir ideas progresistas, es necesario instalar un mecanismo basado en lo más novedoso para la generación, detección, evaluación y mejora de las ideas innovadoras (...) adaptable, tiene que estar provista de un conjunto de antenas sutiles y de gran sensibilidad para captar y decodificar señales y debe ser capaz de responder al instante"4.

Las empresas tienen que desarrollar nuevas habilidades que les permitan detectar y predecir rápidamente las turbulencias en su entorno e identificar las vulnerabilidades y las oportunidades. Hay que crear empresas sólidas y resistentes, flexibles y sostenibles.

Hamel nos enfatiza la dimensión e impacto del cambio en las empresas. Dice que no podemos afirmar nada certero sobre el futuro con una excepción: en algún momento del futuro, todas las empresas se enfrentarán al reto de cambiar de una manera que no tiene precedentes. Lo que más ha cambiado es el propio cambio. Ahora el ritmo del cambio es exageradamente rápido, y por ello el reto es crear organizaciones capaces de renovarse continuamente sin crisis previas que lo justifiquen.

\section{¿QUÉ ES INNOVACIÓN ADMINISTRATIVA?}

Las teorías de la administración son conocimientos organizados, producto de la experiencia de las organizaciones. Sabemos que la sociedad humana está compuesta por organizaciones que proporcionan los medios para atender las necesidades de las personas; las organizaciones transforman recursos en productos y servicios, con criterios de eficiencia y eficacia.

La teoría administrativa y la práctica de la gerencia del siglo XX aseguran la eficiencia y eficacia de las organizaciones mediante las labores siguientes:

- Fijar y programar un objetivo.

- Motivar y alinear el esfuerzo.

- Coordinar y controlar las actividades.

- Desarrollar y asignar el talento.

- Acumular y aplicar el conocimiento.

- Amasar y asignar los recursos.

- Construir y cultivar las relaciones.

- Equilibrar y satisfacer las exigencias de los actores interesados.

En este sentido, podemos calificar de innovación administrativa cualquier cosa que modifique drásticamente la manera cómo se realiza este

4 Ohmae, Kenichi. (2005). Págs 322, 323, 326, 329 y 330. 
trabajo de gerencia, o que modifique ostensiblemente las formas de organización y, con ello, promueva los fines de la empresa ${ }^{5}$.

Mientras que la innovación operativa gira alrededor de los procesos del negocio (compras, producción, comercialización, despacho de pedidos, servicio al cliente, etc.), la innovación administrativa va dirigida a los procesos de gestión de la compañía que determinan la manera cómo se realiza el trabajo cotidiano de administrar. Algunos de los procesos más comunes son:

- Planeación estratégica.

- Elaboración de presupuestos de capital.

- Gestión de proyectos.

- Contratación y ascensos.

- Capacitación y desarrollo.

- Comunicaciones internas.

- Gestión del conocimiento.

- Evaluaciones periódicas de desempeño.

\section{DE LA INNOVACIÓN A LA VENTAJA}

Para crear una empresa adaptable, los gerentes tienen que preocuparse por eliminar los aspectos improbables de muchas ideas descabelladas; sólo pocas serán dignas de inversión, y un número más reducido producirá beneficios.

"La innovación de la gestión empresarial tiende a traducirse en una ventaja competitiva cuando se cumplen una o más de tres condiciones: que la innovación esté apoyada en un principio administrativo novedoso, el cual cuestione una ortodoxia de vieja data; que la innovación sea sistémica y abarque una amplia gama de métodos y procesos; y que la innovación forme parte de un programa constante de invención acelerada que permita la acumulación del progreso en el tiempo"

La innovación administrativa cuestiona los dogmas de la gestión empresarial, muchas veces tan profundamente arraigados como invisibles $\mathrm{y}$, al parecer, atados a experiencias exitosas del pasado.
Una fortaleza de estas innovaciones es que son difíciles de imitar y crean ventajas sistémicas, constituidas por una red de innovaciones individuales que abarcan diversos procesos administrativos para producir un desempeño auténticamente superior en las organizaciones. Asimismo, para crear estas ventajas administrativas, se requiere de mucha perseverancia, trabajo duro y un compromiso perdurable.

La innovación administrativa permite una mayor creación de valor y posibilidad de defensa contra la competencia en una jerarquía de tipos de innovación (innovación operativa, innovación de productos, innovación estratégica, e innovación administrativa); así tenemos que cada una de ellas contribuye al éxito pero "cuando se centra en problemas grandes y complejos, la innovación administrativa es única en cuanto a su capacidad para crear ventajas difíciles de copiar"7.

Se trata de construir una empresa tan ágil como el cambio mismo, con capacidad de renovarse continuamente y sin traumas. El desafío es convertir el cambio profundo en una especie de proceso autónomo para construir organizaciones capaces de renovarse continuamente sin necesidad de crisis ${ }^{8}$.

\section{La escasez de alternativas estratégicas.}

Para escapar de la inercia de los modelos empresariales sujetos a desafíos económicos, una organización necesita una serie de alternativas estratégicas nuevas pero para ello se debe contar con un proceso disciplinado para generar alternativas. Es decir, hay que construir una empresa adaptable, que supere la falta de flexibilidad para asignar recursos generadores de un portafolio variado de alternativas estratégicas radicales ${ }^{9}$.

Éstas son empresas con capacidad de reaccionar con rapidez ante un entorno en constante cambio, y construir escenarios y estrategias para ocuparse de riesgos anticipados y, por otra parte, explotar oportunidades. Requieren que sus líderes inculquen nuevos comportamientos estratégicos y nuevas disciplinas en la organización ${ }^{10}$.

5 Hamel y Breen. (2008). Pág. 23.

6 Op. cit. Pág. 34.

7 Op. cit. Pág. 44.

8 Op. cit. Pág. 57.

9 Op. cit. Pág. 61.

10 Kotler. (2009). Pág. 122. 


\section{Crear una empresa donde todo el mundo dé lo mejor de sí mismo.}

En un mundo donde la adaptabilidad y la innovación se han convertido en una condición del éxito competitivo, las empresas tienen el desafío de reinventar los sistemas administrativos para que sirvan de inspiración para que los seres humanos traigan todas sus capacidades (obediencia, diligencia, conocimiento e intelecto, iniciativa, creatividad, pasión) consigo al trabajo día tras día ${ }^{11}$.

\section{Exceso de gestión, escasez de libertad.}

Si bien las herramientas de la administración pueden obligar a las personas a ser obedientes y diligentes, no sirven para fomentar la creatividad y el compromiso. ¿Cómo ampliar el alcance de la libertad de los empleados con menos supervisión pero sin sacrificar la claridad, la disciplina y el orden?

\section{Exceso de jerarquía, escasez de comunidad.}

Las jerarquías son muy buenas para agregar esfuerzos y coordinar las actividades de muchas personas cuyas funciones son muy diversas, pero no son muy buenas para movilizar esfuerzos ni para inspirar a las personas a dar mucho más de sí mismas ${ }^{12}$. ¿Cómo crear una compañía en donde la unión se base en un espíritu de comunidad y no en el aparato burocrático?

\section{IMAGINAR EL FUTURO DE LA ADMINISTRACIÓN}

Generalmente el progreso económico es de cuatro tipos de innovación: la innovación social, la institucional, la tecnológica y, finalmente, la innovación de la administración. Fue gracias a la innovación de la gestión que realmente se generó un verdadero crecimiento económico, con aumento de la productividad y división del trabajo, aplicando la eficiencia.

Ya van más de 100 años de incremento en capital y productividad. En un principio ese era el problema que la administración debía resolver: encontrar una forma para que las personas hagan una y otra vez la misma tarea, reduciendo los factores variables y aumentando la eficiencia.
La eficiencia sigue siendo un punto crítico; es muy difícil tratar de crear una ventaja en base a la eficiencia operacional ya que siempre aparecen nuevos competidores que pueden llevar sus activos y recursos a un país donde la mano de obra tiene un costo mucho menor o donde la energía no es tan cara. Eso que solía ser una ventaja hoy es un requisito que no implica una oportunidad. Ahora la innovación en gestión debe focalizarse hacia cómo motivar a las personas; cómo organizar, planificar y manejar sus recursos para hacer que una ventaja competitiva se sostenga en el tiempo.

Para reinventar la administración se requiere de un pensamiento coherente, unos principios nuevos y la sabiduría necesaria; todo integrado en un enfoque sistemático.

Este debe ser un proceso disciplinado que cuestione las ortodoxias afincadas en el pasado. Son difíciles de desterrar porque constituyen un conjunto de creencias muchas veces tácitas y que impiden pensar creativamente e imaginar nuevas prácticas administrativas. Por ejemplo, creencias comunes como "se necesita una crisis para provocar un cambio profundo", "se necesita un líder fuerte para impulsar el cambio" o "el cambio comienza desde arriba”, etc., se pueden analizar críticamente haciendo varias preguntas correctas como ¿es ésta una creencia que vale la pena cuestionar?, ¿obstaculiza algún atributo importante de la organización que quisiéramos fortalecer?, ¿es una creencia válida universalmente?, ¿hay ejemplos contrarios?, ¿de qué manera favorece esta creencia los intereses de sus adherentes?, ¿podemos imaginar alternativas?

Tenemos que establecer unos principios gerenciales diferentes capaces de iluminar nuevos cambios. Para este propósito hay que interrogarse sobre cuáles son los principios más profundos de la administración.

Las prácticas y los procesos de la administración moderna se han construido alrededor de un núcleo pequeño de principios modulares: estandarización, especialización, jerarquía, alineación, planeación y control, y el uso de premios extrínsecos para moldear el comportamiento humano ${ }^{13}$.

11 Hamel y Breen. (2008). Págs. 77 y 78.

12 Op. cit. Pág. 82.

13 Op. cit. Pág. 201. 
Cuadro $\mathrm{N}^{\circ} 1$

Los principios de la administración moderna

\begin{tabular}{|c|c|c|}
\hline Principio & Aplicación & Objetivo \\
\hline Estandarización & $\begin{array}{l}\text { Minimizar las variaciones con res- } \\
\text { pecto a la norma en lo que se refiere } \\
\text { a los insumos, los productos y los } \\
\text { métodos de trabajo. }\end{array}$ & $\begin{array}{l}\text { Cultivar las economías de escala, } \\
\text { la eficiencia, la fiabilidad y la cali- } \\
\text { dad de la producción. }\end{array}$ \\
\hline $\begin{array}{l}\text { Especialización (de las tareas y } \\
\text { funciones) }\end{array}$ & $\begin{array}{l}\text { Agrupar las actividades semejantes en } \\
\text { unidades organizacionales modulares. }\end{array}$ & $\begin{array}{l}\text { Reducir la complejidad y acelerar } \\
\text { el aprendizaje. }\end{array}$ \\
\hline Alineación de las metas & $\begin{array}{l}\text { Establecer objetivos claros por medio } \\
\text { de una cascada de metas secundarias } \\
\text { y métricas de apoyo. }\end{array}$ & $\begin{array}{l}\text { Garantizar que los esfuerzos } \\
\text { individuales concuerden con las } \\
\text { metas impuestas desde arriba. }\end{array}$ \\
\hline Jerarquía & $\begin{array}{l}\text { Crear una pirámide de autoridad ba- } \\
\text { sada en un rango limitado de control. }\end{array}$ & $\begin{array}{l}\text { Mantener el control sobre una } \\
\text { amplia gama de operaciones. }\end{array}$ \\
\hline Planeación y control & $\begin{array}{l}\text { Pronosticar la demanda, presupuestar } \\
\text { los recursos y programar las activida- } \\
\text { des para luego registrar y corregir las } \\
\text { desviaciones con respecto al plan. }\end{array}$ & $\begin{array}{l}\text { Establecer un flujo de opera- } \\
\text { ciones regulares y previsibles; } \\
\text { cumplir los planes. }\end{array}$ \\
\hline Retribuciones extrínsecas & $\begin{array}{l}\text { Proporcionar premios económicos a } \\
\text { las personas y los grupos por cumplir } \\
\text { con los resultados especificados. }\end{array}$ & $\begin{array}{l}\text { Motivar el esfuerzo y garantizar } \\
\text { el cumplimiento de las políticas } \\
\text { y las normas. }\end{array}$ \\
\hline
\end{tabular}

Fuente: Hamel y Breen (2008). Pág. 202.

El taylorismo se unió con la notable expansión de la industria y con otra innovación revolucionaria de inicios del siglo XX: la línea de montaje de Henry Ford. Con ella se elevaron al más alto grado los principios de la producción en masa, que son la fabricación de productos no diferenciados en grandes cantidades, las piezas estandarizadas y el trabajador especializado.

El proceso administrativo se ha desarrollado a partir de las ideas de Fayol, quien consideraba a la empresa como un sistema racional de reglas y autoridad, y a la administración como una función distinta de las demás tareas de la empresa como las finanzas, la producción y la distribución. Señaló las cinco funciones: planeación, organización, dirección, coordinación y control.

En "La práctica de la administración”, Drucker hizo énfasis en la necesidad de definir objetivos y evaluar los resultados en áreas clave de desempeño.

En cuanto a modelos de organización, varias investigaciones desde la década de los 60 permitieron identificar modelos alternativos (organizaciones flexibles, aprendizaje organizacional) con el ideal burocrático weberiano (organizaciones jerarquizadas, burocráticas y especializadas).

Estos principios fueron planteados por los pioneros del pensamiento empresarial a comienzos del siglo XX para garantizar un control y eficiencia que facilitara la solución de la pregunta: ¿cómo maximizar la eficiencia y la fiabilidad de las operaciones en las empresas de gran escala?, y la aplicación de esos principios impulsó la prosperidad económica.

"Sin embargo, si la meta es crear organizaciones altamente adaptables y totalmente humanas, esos principios son insuficientes $y$ muchas veces tóxicos. A pesar de todos sus beneficios, la especialización tiende a limitar el aprendizaje expansivo emanado de las ideas novedosas (...) la búsqueda de una estandarización cada vez mayor puede transformarse en un afecto malsano por la obediencia rigurosa, donde todo lo nuevo y atrevido se percibe como una desviación peligrosa de los procedimientos operativos normalizados. El énfasis excesivo en la alineación y congruencia puede coartar la búsqueda de oportunidades (...). Los rituales complicados de planeación y control pueden 
adormecer a los ejecutivos (...) y a mostrarse indiferentes a las discontinuidades para las cuales hay pocos precedentes (....) la fe ciega en la eficacia de la retribuciones económicas puede impedirles (...) reconocer el poder del propósito y la pasión como mecanismos generadores de esfuerzo individual" 14 .

Lo que más frena la innovación en las empresas no es la falta de riesgos; el auténtico freno a la innovación es el lastre de los viejos modelos mentales. En general, los gerentes de gran experiencia tienen invertida una buena parte de capital emocional en la estrategia existente, y la Alta Dirección, a menudo con sus visiones dogmáticas, suelen ser los que deciden qué ideas se ponen en marcha y cuáles se bloquean.

Efectivamente, desde las últimas décadas del siglo anterior, se han producido cambios en todos los tipos de entornos: competitivo, tecnológico, económico y social, que llevaron al surgimiento de nuevos conceptos y técnicas para administrar las organizaciones.

La revolución digital ha generado sustitución y potenciación de las funciones humanas de decisión, comunicación e información por computadoras. Se han consolidado los trabajadores de servicios y del conocimiento, y los profesionales liberales son más numerosos que los operarios clásicos. El trabajador especializado ha sido sustituido por grupos de trabajadores autodirigidos y polivalentes con educación de nivel superior. Las grandes estructuras organizacionales están siendo reemplazadas por estructuras organizacionales esbeltas. Antes el énfasis era la eficiencia, ahora es la orientación a la competitividad, y el interés de las empresas se orienta hacia la ética y responsabilidad social.

Algunos cambios más los hemos percibido de manera paulatina: a fines del siglo XX se venía reconociendo que la Alta Dirección definía la estrategia pero no siempre la explicaba bien a los trabajadores; había una cierta obsesión por medir, pero quizá se desatendía lo que era más difícil de medir ya que los planes de acción se incumplían con frecuencia y además los directivos se centraban principalmente en el corto plazo; se predicaba la orientación al cliente, pero se practicaba más la orientación a la jerarquía empresarial; a menudo las buenas ideas se desvirtuaban en la aplicación; quizá faltaba autocrítica; tal vez sobraba complacencia; se reprimía la crítica -incluso la constructiva- de los empleados; el tiempo se ocupaba más en las explicaciones a dar que en los resultados a obtener; se abusaba de las reuniones; se trabajaba bajo demasiada presión; se atendía sobre todo al marcador (indicadores financieros) y en menor medida al campo de la competitividad...

Para enfrentar los retos del siglo XXI el imperativo más importante para la administración y las organizaciones es la adaptabilidad e innovación para alcanzar el éxito competitivo en un mundo de cambios cada vez más acelerados.

De manera general, la administración, en su calidad de conductora de los esfuerzos organizacionales, siempre ha respondido -desde su surgimiento como ciencia- a la mejora de la relación entre la organización y su entorno orientándose, de manera pertinente, a la meta de resolver la contradicción existente entre una situación externa y la capacidad de adaptarse a ella y, eventualmente, a la capacidad de cambiarla en aras de un crecimiento gradual y continuo.

Desde los años 90 existen nuevas características de las empresas y contenidos del pensamiento administrativo $^{15}$ :

- Características del entorno. Globalización y revolución tecnológica, dinamismo, fuerte incertidumbre, ciclos de vida de los productos cada vez más cortos.

- Objetivos de la dirección. Valor para los interesados (accionistas, clientes y proveedores, sociedad), marketing de relaciones, orientación al mercado.

- Desarrollo de la empresa. Estructura (empresa global, empresa red, franquicias, redes de empresas, alianzas estratégicas), y estrategia (comercio electrónico entre empresas y mercados de consumidores).

- Conceptos estratégicos. Recursos y capacidades organizativas, conocimiento, aprendizaje e innovación, capacidades dinámicas, flexibilidades, modularidad, cambio estratégico, mejora continua, ambiguiedad causal.

- Técnicas. Gestión del conocimiento y de la innovación, gestión de calidad total, bench-

14 Hamel y Breen. (2008). Pág. 203.

15 Valdaliso. (2008). Págs. 400-401. 
marking, nuevas tecnologías de la información, competencia por los estándares, ventajas del pionero.

- Metodología de la investigación en dirección estratégica. Enfoque basado en los recursos, énfasis en los aspectos internos.

El nuevo modelo de administración tiene varios principios elementales. Uno de estos principios es la libertad. Se pueden tener organizaciones con alto grado de independencia y aún así mantener un control jerárquico en la cima. La pregunta es entonces: ¿cómo damos a la gente esa libertad y evitamos que la organización se vuelva un gran caos?

Otro principio es la variedad. El mundo actual se vuelve cada vez más cambiante e impredecible. Ya no puede planearse de acá a 10 o 20 años. Es importante tratar de probar cosas nuevas, experimentar con nuevas formas de bajo costo pero de forma continua para ver qué funciona y qué no funciona.

El tercer principio es comenzar a considerar a la organización como un mercado. Salvo en casos donde hay mucha intervención y donde el mercado no fluye naturalmente, el mercado suele ser un ejemplo de cómo los recursos se van acomodando solos -en la forma más eficiente- sin la necesidad del alto impacto de un comandante. En el largo plazo, el mercado siempre sale ganando frente a las organizaciones.

La experiencia de los modelos de organización social nos enseña que cuanto más concentrado está el poder político, menos resistente será. En el mercado, el poder está distribuido en muchos polos; es decir, que muchas personas -al mismo tiempo- están tomando decisiones, generando ideas sobre qué comprar y dónde invertir. En una jerarquía la toma de decisiones se reduce a un pequeño grupo de personas que determinan una estrategia y dirigen la organización hacia un rumbo que puede ser peligroso en un mundo con tan poca continuidad.

Otro elemento importante es la fe. Cuando se toma distancia y se observa la historia de la humanidad, queda claro que la fe es el verdadero sello del ser humano. Quizás haya menos confianza en la religión, pero las personas aún creen en algún tipo de ser supremo o en el poder de lo espiritual. La realidad es que las personas necesitan que su vida tenga un sentido. Muchas organizaciones ansían ver cambios pero no comprenden que la gente solo cambia por las cosas que verdaderamente le importan. Si quieren generar una postura proactiva y reactiva en su gente, tienen que encontrar y brindar a su gente un verdadero sentido para que ese cambio ocurra.

Para aplicar los nuevos principios de la administración (ver Cuadro $\mathrm{N}^{\circ} 2$ ), proponemos las siguientes preguntas a manera de reflexión:

- Vida/Diversidad. ¿Cómo incorporarían mayor diversidad de información, puntos de vista y opiniones en este proceso? ¿Cómo diseñarían el proceso que facilite el desarrollo continuo de nuevas alternativas estratégicas y fomente la experimentación constante?

- Mercados/flexibilidad. ¿Cómo rediseñarían este proceso para aprovechar la sabiduría del mercado y no solo la sabiduría de los expertos? ¿Cómo podría utilizarse este proceso

Cuadro $\mathrm{N}^{\circ} 2$

Los nuevos principios de la administración

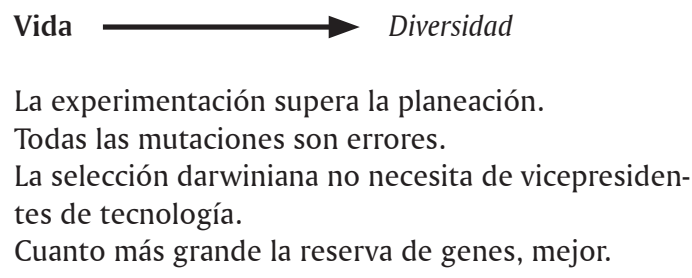

La experimentación supera la planeación.

Todas las mutaciones son errores.

La selección darwiniana no necesita de vicepresidentes de tecnología.

Cuanto más grande la reserva de genes, mejor.

\section{Mercados $\longrightarrow$ Flexibilidad}

Los mercados son más dinámicos que las jerarquías. Basta con construir un mercado para que lleguen los innovadores.

Eficiencia operativa $\neq$ eficiencia estratégica.

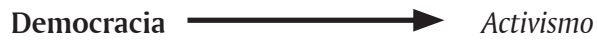

Los líderes son responsables ante los gobernados. Todo el mundo tiene derecho a disentir. El liderazgo es distribuido.

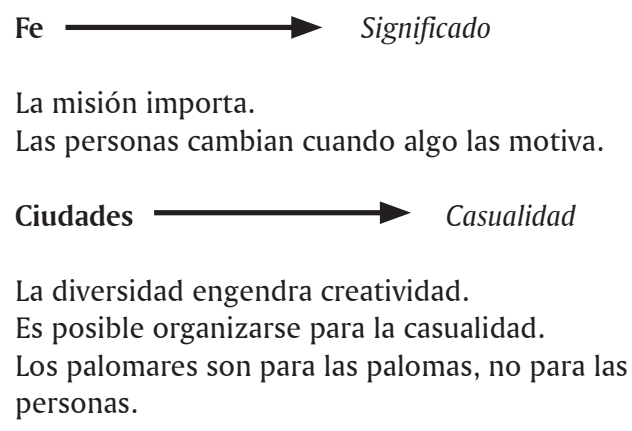

Fuente: Hamel y Breen. (2008). Pág. 242. 
para acelerar la reasignación de los recursos a las iniciativas nuevas? ¿Cómo facilitarles a los innovadores la consecución de los recursos para llevar adelante sus ideas?

- Democracia/activismo. ¿Cómo modificarían el proceso para fomentar en vez de sofocar la disensión? ¿Qué harían para que el proceso responda más a las necesidades e intereses de los trabajadores de primera línea? ¿Cómo brindar a la gente más voz a la hora de forjar la política y la estrategia?

- Fe/significado. ¿Cómo utilizarían este proceso para ayudar a centrar la atención en las metas de orden superior que nuestra organización afirma tener (o debería tener)? ¿Cómo podría este proceso ayudar a los empleados a identificarse y conectarse con las metas que más les interesan como personas?

- Ciudades/casualidad. ¿Cómo rediseñar este proceso de tal manera que ayude a la organización a ser un lugar de trabajo todavía más emocionante y vibrante, y un imán para el talento creativo? ¿Cómo podría utilizarse este proceso para facilitar la colisión de ideas nuevas?

Los nuevos principios de la administración están encaminados a fomentar la adaptabilidad, a aprender sobre los factores que la determinan, pero tampoco hay que despreciar los principios originarios. Al contrario:

“... todas las razones nos inducen a creer que el contraste entre los credos de la administración moderna y los de la administración postmoderna en realidad sí pueden coexistir en una empresa, las dos versiones no son totalmente compatibles. Habrá conflictos"16.

Las ciencias administrativas seguirán proporcionando a las organizaciones principios básicos que se han forjando de manera acumulativa frente a la dialéctica de las teorías y las prácticas administrativas. Entre ellos tenemos:

- Autonomía. La toma de decisiones, con una plena correspondencia entre la responsabilidad y autoridad.

- La competencia humana. La buena administración depende del manejo eficaz y eficiente de los recursos humanos de la organización.
- Objetividad. Sólo con un conocimiento profundo de los factores que explican el desempeño de la organización será posible actuar objetivamente en favor de su mejora.

- Orientación a la cualidad sistémica. El objetivo de la organización define la finalidad para la cual se han ordenado los medios y sus relaciones.

- Mejora. La máxima potencia de una organización se logra cuando se mantiene de manera continua el movimiento de mejora.

Tenemos otros principios:

- Situación límite. Las organizaciones se enfrentan de manera constante a situaciones límites que se oponen a su mejora.

- Contingencia. La administración es consecuencia del análisis de las condiciones concretas de la organización en cuestión, para derivar de ahí la forma de actuar de manera práctica en cada caso.

- Restricción. Toda organización ve frenada la tendencia creciente de su desempeño por alguna limitación introducida en su operación que define la frontera del sistema y hace posible explicar las condiciones bajo las cuales opera.

- Intercambiabilidad. La meta de la organización puede cambiar de acuerdo a la etapa de desarrollo por la que transita.

- Suficiencia. La clave consiste en poseer y controlar los recursos y competencias centrales que constituyen la esencia de la organización.

- Conectividad. Toda organización se forma únicamente como resultado de la acción recíproca de las partes que la integran.

- Unidad de administración y la información. La administración se materializa en la toma de decisiones pero solo se puede decidir sobre lo que se conoce, y para ello hace falta determinada cantidad y calidad de información.

- Medición. Si algo no se puede medir tampoco se podrá administrar y, por lo tanto, poco podrá hacerse en favor de su mejora.

Como sucedió con la producción en masa y el fordismo, la aplicación de los sistemas flexibles

16 Hamel y Breen. (2008). Págs.243 y 342. 
se ha realizado de formas muy variadas. Una vez más, no hay una tendencia clara a la convergencia, aunque el denominador común en todos los sectores es el aumento de la flexibilidad del trabajo y el empleo ${ }^{17}$.

\section{EMPRESAS APTAS PARA EL FUTURO}

"Por primera vez desde los albores de la era industrial, la única forma de construir una empresa apta para el futuro es asegurarse de que sea también apta para los seres humanos. Esta es su oportunidad: construir un modelo administrativo del siglo XXI que realmente fomente, honre y aprecie la iniciativa, la creatividad y la pasión de los seres humanos - esos ingredientes esenciales y delicados para el éxito de los negocios en este nuevo milenio"18.

Este nuevo modelo debe aprender a coordinar los esfuerzos de miles de individuos sin crear una jerarquía opresiva de jefes y supervisores; a controlar los costos con firmeza sin asfixiar la imaginación humana, y a crear organizaciones donde la disciplina y la libertad no se excluyan mutuamente.

Las empresas deben emprender un largo y firme proceso para construir conocimiento colectivo y disponer de habilidades para crear culturas que gocen de cimientos profundamente enraizados en ellas, con la finalidad de llegar a ser, a largo plazo, empresas de negocios sostenibles ${ }^{19}$.

\section{CONCLUSIONES}

1. Existe un nuevo escenario económico caracterizado por la turbulencia de alta intensidad. Actualmente podemos esperar mayores sacu- didas y disrupciones que causan elevado y generalizado riesgo, así como gran incertidumbre en los negocios.

2. La innovación de la gestión empresarial se convierte en una ventaja competitiva cuando se cumplen una o más de tres condiciones: que la innovación esté apoyada en un principio administrativo novedoso; que la innovación sea sistémica y abarque una amplia gama de métodos y procesos; y que la innovación permita la acumulación del progreso en el tiempo.

3. Al igual que la eficiencia, la escala y el control representaron desafíos para las empresas del siglo XX, los retos más importantes de las empresas en el siglo XXI son: acelerar la renovación estratégica tanto en las organizaciones grandes como en las pequeñas; convertir la innovación en el trabajo de todos, y crear un entorno laboral muy motivador para la creatividad y el compromiso. Tampoco se trata de abolir el control, se necesita la regulación.

\section{BIBLIOGRAFÍA}

Hamel, Gary y Breen, Bill. (2008). El Futuro de la Administración. Bogotá, Grupo Editorial Norma.

Kotler, Philip y Caslione, John A. (2009). La Ciencia del Caos. Barcelona, Gestión 2000.

Ohmae, Kenichi. (2005). El próximo escenario global. Desafíos y oportunidades en un mundo sin fronteras. Bogotá, Grupo Editorial Norma.

Valdaliso, José María y López, Santiago. (2008). Historia económica de la empresa. Barcelona, Crítica.

17 Valdaliso. (2008) .Pág. 474.

18 Hamel y Breen. (2008). Págs. 343-344.

19 Kotler. (2009). Pág. 160. 